\title{
QUEEN'S
UNIVERSITY
BELFAST
}

\section{Effectiveness of child protection training for pre-service early childhood educators}

McKee, B., \& Dillenburger, K. (2012). Effectiveness of child protection training for pre-service early childhood educators. International Journal of Educational Research, 53, 348-359. https://doi.org/10.1016/j.ijer.2012.04.008

\section{Published in:}

International Journal of Educational Research

\section{Document Version:}

Peer reviewed version

\section{Queen's University Belfast - Research Portal:}

Link to publication record in Queen's University Belfast Research Portal

\section{Publisher rights}

Copyright 2017 Elsevier.

This manuscript is distributed under a Creative Commons Attribution-NonCommercial-NoDerivs License

(https://creativecommons.org/licenses/by-nc-nd/4.0/), which permits distribution and reproduction for non-commercial purposes, provided the author and source are cited.

\section{General rights}

Copyright for the publications made accessible via the Queen's University Belfast Research Portal is retained by the author(s) and / or other copyright owners and it is a condition of accessing these publications that users recognise and abide by the legal requirements associated with these rights.

Take down policy

The Research Portal is Queen's institutional repository that provides access to Queen's research output. Every effort has been made to ensure that content in the Research Portal does not infringe any person's rights, or applicable UK laws. If you discover content in the Research Portal that you believe breaches copyright or violates any law, please contact openaccess@qub.ac.uk. 


\title{
Effectiveness of child protection training for pre-service early childhood educators
}

McKee, B. \& Dillenburger, K. (2012) International Journal of Educational Resarch, 51

\begin{abstract}
International evidence confirms that early childhood educators can enter professional practice unprepared for child protection due to inadequate pre-service preparation. This paper makes an original contribution by using the Child Protection Questionnaire for Educators (CPQE) to examine the pre- and post- intervention child maltreatment and protection knowledge of early childhood and primary teaching students. While students' knowledge increases significantly after participating in a child protection training programme, Pastoral Pathways, as part of their undergraduate study, post-intervention scores vary between groups. The study provides evidence of programme effectiveness and future training needs of pre-service educators. Findings are relevant to teacher educators and child care training providers in relation to programme content development and evidencing knowledge and skills acquisition.
\end{abstract}

Keywords: pre-service, educators, maltreatment, protection, training 


\section{Introduction}

Early childhood educators' knowledge and understanding of child maltreatment and protection has far reaching implications for children in early childhood settings such as daycare, nursery and the early years of school for two main reasons. First, complex traumatic experiences such as child abuse, neglect and exposure to family violence (child maltreatment) can influence the way in which children learn and grow. It is therefore of critical importance that early childhood educators understand the context and impact of child maltreatment on children's psychosocial development (Finkelhor, 2008). When children feel safe and loved and are protected from all forms of harm, learning opportunities can be realised effectively. Conversely, maltreatment affects learning processes adversely, impacts negatively on children's behaviour, and makes it difficult for young children to develop social relationships in the early years of school. These behaviours are very often not understood by educators who, if unprepared, can cause further harm to the child as a result of inadequate responses (Creedan, 2008).

Second, besides the family, early childhood educators are in contact with children for longer periods of time than any other professional. While their primary purpose is to contribute to children's learning, development and wellbeing, this places early childhood educators in the unique position to contribute also to early identification and response when developmental needs are compromised through maltreatment and/or trauma (McKee \& Dillenburger, 2009). Younger children are at increased risk of exposure to family violence (Holt, Buckley \& Whelan, 2008), and are more vulnerable to abuse and neglect (Lazenbatt, 2010) when compared to older children or adolescents. Of greater concern is that international data highlight how child abuse fatalities occur most frequently during early childhood (Gilbert, Spatz Widom, Browne, Fergusson, Webb \& Janson, 2009; World Health Organisation [WHO], 2002). In support of this trend, United Kingdom [UK] prevalence data indicate that infants are significantly more at risk of death by maltreatment than any other age group across the lifespan (Bunting, 2011; UK Department of Education, 2010). 
Accordingly, it is most likely that early childhood educators are the first professionals to detect child protection concerns and are able to alert other professionals, such as social workers or the police (Walsh \& Farrell, 2008). Unfortunately educators of younger children can lack sufficient preparation for their child protection role (Goldman, 2007) and have been, in many cases, responsible for failing to report more cases of maltreatment when compared with other professional groups (Gilbert, Kemp, Thoburn, Sidebotham, Radford, Glaser \& MacMillan, 2009; Kenny, 2004). For these reasons, pre-service preparation of early childhood educators for their child protection role in the early years of school is important. The study reported here used the Child Protection Questionnaire for Educators (CPQE) to measure pre-service (student) early childhood educators' knowledge of six key child maltreatment and protection issues, pre- and post- training.

\section{Literature}

\subsection{The impact of trauma on children: a developmental perspective}

In order to fully understand the context and impact of child maltreatment early childhood educators have to grasp key insights into how trauma affects children and their learning. In one of the first longitudinal studies of traumatized children, Terr (1990, p. 8) explains that trauma occurs "when a sudden, unexpected, overwhelming intense emotional blow or a series of blows assaults the person from outside" and adding that "traumatic events are external, but they quickly become incorporated into the mind". More recently, international trauma experts agree that children's experiences of abuse and neglect, family violence or exposure to multiple adversities can result in later psychological, cognitive and behavioural problems especially if not detected early (Bevans, Cerbone \& Overstreet, 2005; Creeden, 2008; Kasiram \& Khosa, 2008).

It has been suggested that maltreated children who routinely operate in survival mode are at increased risk of exposure to a complex set of chemical 
and neurological events in the brain known as the stress response (Bevans et al., 2005). Through the sympathetic nervous system the stress response activates a natural instinct to prepare to fight, to flee from the unsafe event or to freeze (Creeden, 2008). During this time there is heightened anxiety arousal and while these responses to stress can be constructive, when a child lives in continual stress, survival responses can become a regular mode of functioning (Perry, 2006). What this means to the maltreated child is that, because of a chronic state of fear, they may react to the world as if they are in danger even when dangers are not present.

From a neuroscientific point of view, this chronic state of fear can impede development of critical brain functions including memory, problem solving, language and higher order thinking (Creeden, 2008). Van der Kolk (2005) explains that for maltreated children there are no logical cause-and-effect relationships since cognitive development has been occurring in an abusive, inconsistent and unpredictable environment. He adds that normal explorative play, the way in which young children learn and develop best, is compromised for abused children; therefore, the ability to role play another person's perspective is more limited (van der Kolk, 2005). Additionally, it is thought that a child's ability to organise academic tasks depends on their ability to organise narrative material (Whitehead, 2003). During childhood, memories and information are encoded episodically as random events rather than as a coherent narrative. Children then develop to sequential semantic memory but usually in an environment marked by consistent, predictable routines and familiar, reliable caregivers. Maltreated children, unfortunately, are deprived of such a stable environment and thus the move into a more sequential ordering of the world is more difficult (Bevans et al., 2005).

In addition to academic performance, trauma theory suggests that maltreatment can impair the development of children's ability to regulate their emotions and to control compulsive behaviours. According to Geddes (2003) displays of inappropriate behaviour in the classroom are, for some children, their only form of communicating distress and anxiety. Inevitably, these behaviours viewed by other children as naughty or inappropriate can disturb a 
developing relationship with a friend (Perry, 2006). This is seen as a longitudinal issue as disengagement from prosocial peers has been known to lead to increased risk of later behavioural problems (Swenson \& Chaffin, 2006) and highlights the need for education-based efforts on improving behaviour and relationships of maltreated children. Werlkerle, Leung, Wall, MacMillan, Boyle, Trocme and Waichter (2009) go so far as to suggest that, based on Bandura's (1977) social learning theory whereby children learn much of their behaviour through imitating the behaviour of others, an environment of maltreatment may actively promote abusive behaviour as the correct mode of conduct. In support of this possibility, Anthonysamy and Zimmer-Gembeck (2007) studied the peer relationships among 400 young children (4-6 year olds) and found that maltreated children were rated by their classmates as being significantly less popular because of their behaviour i.e. they were deemed to be more physically and verbally aggressive, withdrawn and less prosocial.

Unsurprisingly, these behaviours or coping mechanisms (Geddes, 2003) can frustrate educators and evoke exasperated reprisals. These responses can both strengthen expectations of confrontation in the classroom setting and reinforce a negative self image (van der Kolk, 2005). Prompted by internal states not always understood by the child, and very often not recognised by the educator, abused children can appear demanding, unpredictable and ambivalent. Some schools struggle to understand the behaviour of abused children and may be quick to reprimand or suspend children without looking for reasons causing the behaviour (Taylor \& Siegfried, 2005).

The evolving understanding of neurodevelopment and how trauma can affect learning highlights the most important aspects of working with maltreated children i.e. the importance of providing a safe and secure environment in which the child's fundamental needs for emotional security and physical safety are met and the fact that the damage that maltreatment causes can be mitigated and alleviated when educators understand the context and impact of maltreatment. 
In recent years the education sector has seen significant legislation and policy developments with the intention of meeting the safety and welfare needs of children by improving professional practice around child protection. These needs, which are enshrined in the United Nations Convention on the Rights of the Child [UNCRC] (UN, 1989), are now formally embedded in England and Wales through the Children Act 2004, incorporated into the Standards for Classroom Teachers and form part of the framework of Ofsted inspection in schools (Kirk \& Broadhead, 2007). Other detailed practice guidelines highlight safeguarding (including child protection) as a core knowledge requirement for the wider pre-service child care workforce (HM Government, 2005; Quality Assurance Agency [QAA], 2007), and emphasise the importance of multiagency collaboration in child protection (Department for Education and Skills [DfES], 2006).

In Northern Ireland, these developments are evident in the 'Ten Year Strategy for Children and Young People' (Office of the First Minister and Deputy First Minister [OFMDFM], 2006), the overarching policy framework for improving outcomes for children, and reflected in key legislation including the Children (Northern Ireland) Order 1995, the Education and Libraries (Northern Ireland) Order 2003, and the Safeguarding Vulnerable Groups (Northern Ireland) Order 2007. The Safeguarding Board Bill for Northern Ireland 2009 more recently placed a statutory duty on the child care workforce (including education) to safeguard the welfare of children (Safeguarding Board (Northern Ireland) Act 2011). This duty to safeguard features also in other practice guidance for schools and early years settings including Department of Education circular 1999/10 (DENI, 1999), the 'School Governors Handbook: Safeguarding and Child Protection' (Child Protection Support Services for Schools [CPSSS] \& DE, 2010), 'Co-operating to Safeguard Children' (Department of Health, Social Services and Personal Safety [DHSSPS], 2003) and Area Child Protection Committees [ACPC] 'Regional Policy and Procedures' (ACPC, 2005), and 'Amendments' (ACPC, 2008). 
Despite these policy, legislative and guidance developments, the position of pre-service educators' remains unclear even though they inevitably work directly with a child in need and/or experience disclosure of abuse (Sinclair Taylor \& Hodgkinson, 2001). Efforts to address this gap in pre-service provision have been made elsewhere. For example, the UK Department of Health [DoH] $(\mathrm{DoH}, 2002$, p. 4) report called for child protection and safeguarding training to meet the needs of the children's workforce and argued for the establishment of "minimum expectations, standards and curriculum for child protection training as part of the core professional training of all professionals working with children and young people (e.g. teacher training)".

The National Society for the Prevention of Cruelty to Children [NSPCC] (2004) responded by outlining how teachers could be left facing disciplinary action or dismissal if they failed to recognise and act on abuse and neglect. It called on government to ensure that all teachers were fully trained in child protection as part of their professional qualification. This changed in 2006 when the Green Paper 'Every Child Matters' (ECM) (DfES, 2003), legally mandated by the Children Act 2004, made it a requirement for teacher education courses in England and Wales to provide pre-service preparation in child protection and safeguarding (DfES, 2006). Thus, higher education providers are expected to ensure that all those entering the child care profession, including teaching and early years practice, are familiar with legal and policy frameworks, the context and impact of adversity and abuse on children, and responding and reporting procedures in practice (Kirk \& Broadhead, 2007).

Although there is no such legal requirement for child care training providers in Northern Ireland, the need to protect children and safeguard their rights features prominently in the subject benchmark statements for early childhood studies degrees (Quality Assurance Agency [QAA], 2007) and in the overview of teacher competencies provided by the General Teaching Council for Northern Ireland [GTCNI] (GTCNI, 2007). Both documents highlight that students should be provided with opportunities to learn about and understand the context and impact of abuse, how to recognise and respond to factors 
which hinder learning, and how to work collaboratively to support pupils learning when faced with adversity. Beyond that, students rely heavily on higher education providers' interpretation of 'appropriate coverage' in relation to content, duration and location of these topics in undergraduate programmes.

\subsection{Pre-service child protection preparation}

The field of child protection and education has long been a topic of international interest. The more sharply focussed research lens on child protection in the undergraduate curriculum has emerged in recent years but to date remains relatively scant. Available research, primarily conducted in Australia (see Arnold \& Maio-Taddeo, 2007; Walsh \& Farrell, 2008; Walsh, Laskey, Mclnnes, Farrell, Mathews \& Briggs, 2011), Asia (see Briggs \& Potter, 2004; Feng, Chen, Wilk, Yang \& Tetzer, 2009), the United States [US] (see Goldman, 2007; 2010; Goldman \& Grimbeek, 2011; Kenny, 2004; 2007), the United Kingdom [UK] (see Baginsky \& Macpherson, 2005; Bishop, Lunn \& Johnson, 2002; Rossato \& Brackenridge, 2009), with more recent research activity in Ireland (see Buckley \& McGarry, 2010; 2011; McKee, 2009; McKee \& Dillenburger, 2009), consistently shows that pre-service child protection preparation for educators remains sporadic, inconsistent and mostly inadequate.

In the US, for example, Kenny (2004) used the self-report educators and child abuse questionnaire (ECAQ) to explore educators' self-perceived adequacy of pre-service training. Only $34 \%$ of her sample stated that they had received such preparation; of these nearly two-thirds felt that the training was either minimal (43\%) or inadequate (23\%). Along these lines, Goldman (2007) found evidence that undergraduate programmes needed to enhance student teachers preparation for child abuse response and its mandatory reporting in Queensland, Australia. Penter, Cant and Clare's (2005, p. 18) review of child protection training provided in universities across Australia revealed an inconsistent and inadequate approach to "core child protection training" in undergraduate programmes, particularly in "education and teaching". 
Similarly, Arnold and Maio-Taddeo (2007) found that only 1-7 hours of child protection content was offered in teacher education programmes across Australia.

Unsurprisingly newly qualified educators can feel ill-equipped to deal with child protection in practice because they lack confidence in their responding and reporting knowledge (Rossato \& Brackenridge, 2009) and many express concern about their direct response to a suspicion of child abuse (Clarke \& Healey, 2006; Goldman \& Grimbeek, 2009). This lack of knowledge and confidence was found in UK studies by Hodgkinson and Baginsky (2000), Baginsky and Macpherson (2005), and Rossato and Brackenridge (2009) who suggest that an inconsistent approach to pre-service child protection preparation can leave educators feeling anxious and concerned about their child protection role in schools. In Northern Ireland, McKee and Dillenburger (2009) also found considerable gaps in students' child maltreatment and protection knowledge and recommended the development of compulsory training for early childhood and teacher education students from the first year of study.

It seems that while the majority of early childhood educators want to protect the welfare of children in their care, they lack the specific training and preparation, and therefore the knowledge and confidence, to uphold their mandatory child protection duty in education. A key message resonating through this research is the urgent need to develop pre-service child protection content for educators; however there has not been widespread dissemination of established training programmes in child protection preparation (Alvarez, Donohue, Carpenter, Romero, Allen \& Cross, 2010) and studies on pre-service educators child maltreatment and protection knowledge development is limited (Walsh et al., 2011). Against this backdrop, this research explores the pre-service preparation of early childhood educators for their child protection role in the early years of school and, based on students' child maltreatment and protection knowledge development, considers the effectiveness of a pre-service child protection training programme, Pastoral Pathways. 


\section{Method}

\subsection{Aims}

Data reported here are part of a larger multi-method study that developed, assessed and implemented a low intensity 3-year pre-service child protection and safeguarding education programme for student educators for the first time (Pastoral Pathways). Using the Child Protection Questionnaire for Educators (CPQE) (McKee \& Dillenburger, 2009) to assess change in knowledge and skills regarding child maltreatment and protection, the primary purpose of this paper is to assess the child protection training needs of two groups of students before and after involvement in the programme.

\subsection{Research Ethics}

Ethical approval for this study was granted from the Research Ethics Committee, Queen's University Belfast. At all stages of the research efforts were made to adhere to key ethical principles of respecting the rights and dignity of those involved. Guided by ethical principles in educational research (British Educational Research Association [BERA], 2004), careful consideration was given to participating students. Participants were informed verbally and in writing about the nature, design and content of the study. Time was allocated at the start of every contact session to remind students of programme content and at the end of every session for debriefing and to follow up unexpected issues raised during the programme. The programme was delivered by the same academic staff trained and experienced in the sensitive nature of child protection practice, training and education. Participation was voluntary, questionnaires were coded, and individual questions and themes were specific to programme content, rather than personal experiences of participants.

\subsection{Participants}


Students were recruited during a timetabled class in the participating institution. The study was explained in full and those who wished to proceed signed an informed consent form. This included Bachelor of Arts (Honours) Early Childhood Studies students $(n=49)$ (hereafter ECS) and Bachelor of Education (Primary) students ( $n=97$ ) (hereafter TEd) giving a total of $n=146$. Forty-five of these were not included in final analyses for a number of reasons: change of degree pathway mid study, non completion of the questionnaire at all test stages, no student code on returned questionnaire, or unable to attend one or more training sessions with valid reasons provided e.g. interview, medical appointment. Participant details can be seen at Table 1.

(Insert Table 1 here)

Participants represented the typical age, ethnicity, ability and gender constellation found in undergraduate classes in these subjects across the UK (Higher Education Statistics Agency [HESA], 2011).

\subsection{Research Tools}

A low intensity 3-year pre-service child protection training programme (Pastoral Pathways) was developed for pre-service educators. With the exception of a child protection resource pack available to teacher education providers in England (NSPCC, 2003), Pastoral Pathways is the first assessed compulsory pre-service child protection training programme of this duration and for this group of students in the UK. The programme was developed by the first author, embedded where possible into the undergraduate curriculum and delivered to both groups by the same academic teaching staff in the participating institution. Reflecting a child's rights based approach to protection, the programme is set within a legal and policy framework and addresses the context and impact of child maltreatment, and the educators' role in recognition, response and reporting. Programme features, also evident in a range of theoretical and legal frameworks (see for example CPSSS and 
DE, 2007; DENI, 1999; GTCNI, 2007; Lazenbatt, 2010; QAA, 2007; Walsh \& Farrell, 2008) include:

1. The extent and impact of child maltreatment (realities);

2. Vulnerabilities and risk factors for children (risk factors);

3. Signs and symptoms of child abuse, neglect and exposure to family violence (indicators);

4. Recognising child abuse, neglect and violence in the context of education and care settings (recognition);

5. Direct work with children, families and professionals with a focus on response and multiagency collaboration (practice issues); and

6. The legal and policy context with a focus on reporting, a duty of care and legal responsibilities in education (legal and policy context).

The Child Protection Questionnaire for Educators (CPQE) was adapted from the Early Years Questionnaire and Child Protection [EYQCP] (McKee, 2003) and used to measure students' child maltreatment and protection knowledge. It contains the following six key themes that are directly related to the Pastoral Pathways programme content:

1. Realities

2. Risk factors

3. Indicators

4. Recognition

5. Practice issues

6. Legal and policy context.

A total of 30 multiple-choice questions (MCQs) were devised to address these themes (five questions for each of the 6 themes). Each MCQ had four possible answers; three incorrect and one correct drawn from relevant literature and legal and policy directives. For example, the aim of a MCQ within the theme 'Practice issues' was to determine students' knowledge of reporting procedures:

If a child alleges abuse by a parent, educational/group staff should:

(a) Make a referral to social services

(b) Ask the group leader/school principal for advice 
(c) Inform the designated person for child protection/pastoral care

(d) Ask the parent if they can explain the situation.

Prior to completing the CPQE, and in order to eliminate learning not related to the programme, participants were asked to indicate if they had attended other child protection training during the course of the study. The CPQE was piloted with a cohort of final year ECS students; only minor amendments, in terms of terminology within MCQs, were made.

\subsection{Procedure}

The Pastoral Pathways programme was integrated, where possible, into the existing undergraduate curriculum and consisted of six 2-hour contact sessions delivered over 3-years, giving a total of 12-hours dedicated coverage time. When considering a typical course structure, Pastoral Pathways exceeds the average UK allocation to child protection related content in most Teacher Education courses (see Baginsky, 2003; Rossato \& Brackenridge, 2009) as well as some international coverage (see Arnold \& Maio-Taddeo, 2007; 2008; Kenny, 2004). Table 2 shows the sequencing of training sessions and provides a sample of content.

(insert table 2 here)

At the time of the study, the TEd group were expected to attend, learn about and understand three major components of teacher education: curriculum studies, subject studies and education studies. It was within the latter component, education studies, that the Pastoral Pathways was embedded, rather than being contained in a discrete unit of its own, and therefore seen by the students as a compulsory yet integral aspect of Teacher Education. The ECS group were invited to attend training during timetabled classes; some of these were within existing modules (units) and therefore seen as embedded into the degree and some of which were outside of normal contact time with students. Regardless of where students received the 
content, all six Pastoral Pathways themes were addressed through a mix of lectures, seminars and interactive group discussions and activities.

The CPQE was distributed, completed and returned in person during three specially convened classes: in first year at the beginning of the study before any training (pre-test), in second year during the course of the training (midtest), and in third year at the end of the study after all the training was completed (post-test). Pre-test and post-test scores are reported here.

\subsection{Data analysis}

Answers on the questionnaire were scored as correct if participants ticked the box corresponding to the correct answer or the entire box was circled. Answers were marked incorrect if the letter corresponding to an incorrect answer was ticked, if more than one answer was ticked, or if no answer was ticked. There was no negative scoring i.e. correct answers received 1 and incorrect answers received 0.

Preliminary tests were conducted on the data to identify appropriate statistical measures. The normality principle was found to be violated in certain instances. The normality of the distribution was examined by comparing histograms with associated normal curve, skewness and kurtosis values and the normality tests Kolmogorov-Smirnov/Shapiro-lilk. The aggregate scores (pre-test, post-test and the difference between tests) were found to have normal distributions. By contrast, each test area, or questionnaire theme (realities; risk factors; indicators; recognition; practice issues; and legal/policy context), based on a 5-point scale, did not show normal distributions either pre- or post-test. Thus, parametric tests based on normality assumptions such as the independent samples t-test were identified as appropriate for the overall aggregate data, with the non-parametric Mann-Whitney test identified as the appropriate statistical measure to examine differences between questionnaire themes.

\section{Results}




\subsection{Data analysis}

Using the independent samples t-test, no significant difference between pretest scores was found between TEd group $(\mathrm{M}=.461, \mathrm{SD}=.082)$ and ECS group $(\mathrm{M}=.465, \mathrm{SD}=.086)$ [Equal variances assumed] $(\mathrm{t}(99)=.227, \mathrm{p}>0.05)$. The non significant pre-test differences, coupled with the indication that none of the participants engaged in similar training elsewhere during the course of the study, allowed for a general post-test comparison between groups to be made.

On average, TEd group scored higher post-test $(M=.748, S D=.095)$ than $E C S$ group $(M=.621, S D=.106)$. This difference was found to be highly significant $(t(99)=-5.932, p<0.001)$. On average, TEd group scores had a greater increase $(M=.287, S D=.111)$ than $E C S$ group scores $(M=.156, S D=.127)$. This difference was also found to be highly significant $(t(99)=-5.215, p<0.001)$. Table 3 shows results of the CPSE in relation to percentage of correct preand post-test responses for all five MCQs in each of the six CPQE themes, according to the two student groups. Figure 1. illustrates the post-test percentage score for each CPQE theme for each group.

(insert Table 3 and Figure 1 here)

An analysis of the findings, using the Mann-Whitney test, revealed significant differences between pre- and post-test correct scores $(p<0.05)$ in three CPQE themes: risk factors $(p<0.01)$, practice issues $(p<0.001)$ and legal/policy context $(p<0.001)$. Three themes: realities; indicators; and recognition, were found to be not significant $(p>0.5)$. While both groups significantly increased their post-test scores for the whole CPQE, when subject to inferential analysis at post-test only, TEd group scored significantly higher than their ECS counterparts in three CPQE themes: risk factors $(U=714, p<0.05)$, practice issues $(U=264, p<0.001)$, and legal/policy context $(U=492, p 0.001)$ (Table 4). 
Consideration to theme MCQs helps to differentiate the child protection training needs of student groups as well as informing future pre-service programme content.

\subsection{CPQE theme: risk factors}

Four out of five MCQs in this theme were correctly answered by a greater percentage of TEd students than ECS students. These are shown in Table 3 and were related to: childhood physical abuse and parenting styles in adulthood (TEd $50 \%$, ECS $30 \%$ ); lack of social skills in adults and sexual abuse of children (TEd $51 \%$, ECS $37 \%$ ); multiple risk factors for child neglect (TEd 79\%, ECS 57\%); and multiple family adversities as a risk factor for child abuse and neglect (TEd 69\%, ECS 63\%). Marginally more ECS students $(70 \%)$ correctly answered the MCQ related to mental ill-health and emotional abuse compared to the TEd group (69\%).

\subsection{CPQE theme: practice issues}

Four out of five MCQs in this theme were correctly answered by a greater percentage of TEd students than ECS students. The first three were related to: reporting concerns to a designated teacher or person (TEd 79\%, ECS $20 \%$ ); the range of professionals entitled to attend a child protection case conference (TEd 94\%, ECS 23\%); and the inappropriateness of teachers and early childhood educators involvement in child abuse investigations (TEd $79 \%$, ECS $20 \%$ ). The final MCQ was correctly answered by a marginally greater number of TEd (86\%) students compared to ECS (83\%) students. This question was related to the importance of continued observations when the maltreated child returns to school or early years setting.

\subsection{CPQE theme: legal/policy context}

Like the previous two themes, four out of five MCQs were correctly answered by a greater percentage of TEd students than ECS students. These were related to: the paramountcy principle of the Children (NI) Order 1995 (TEd $73 \%$, ECS $57 \%$ ); reporting requirements contained within educational policy (TEd 99\%, ECS 57\%); the role of social care staff in multiagency collaboration 
(TEd 63\%, ECS 33\%); and knowledge of the child welfare checklist contained within the Children (NI) Order 1995 (TEd 76\%, ECS 50\%). The final MCQ in this theme was correctly scored very well by both groups (TEd 99\%, ECS $100 \%$ ) and was related to the unique role and requirements of early childhood educators in child protection.

\section{Discussion of findings}

The aim of this study was to assess the child protection knowledge of two groups of students before and after involvement in a pre-service child protection training programme. While a need for development has already been identified locally (McKee \& Dillenburger, 2009) and internationally (see for example Arnold \& Maio-Taddeo, 2007; Baginsky \& Macpherson, 2005; Goldman, 2010; Kenny, 2007; Walsh et al., 2011), there remains a dearth of research on the impact of training programmes on students' child maltreatment and protection knowledge development. Both groups in this study significantly increased their scores from pre-test to post-test. When post-test scores only were considered, three out of six key child maltreatment and protection themes were identified as significantly different between two student groups: risk factors, practice issues and legal/policy context.

\subsection{Risk factors}

While most students from both groups recognised multiple family adversities as a risk factor for child maltreatment, a considerable number of ECS students failed to recognise risk factors associated with specific abuse types. For example, post-test scores revealed that only a minority recognised risk factors associated with physical abuse, sexual abuse and neglect. A major implication on educational practice is that early intervention will rely on a trauma-sensitive response (van der Kolk, 2005). The nature of response to trauma in children is dependent on a wide range of factors but the most important appears to be educators' understanding of the broader context and impact of maltreatment on children. Part of this repertoire of knowledge includes understanding of risk factors for maltreatment, identification and 
knowing how to respond appropriately (Walsh \& Farrell, 2008). Conversely, lack of knowledge in these areas can contribute significantly to lack of appropriate reporting (Goldman, 2010; Walsh et al., 2011).

If these characteristics of pre-service preparation are valid, then consideration should be given to the QAA (2007, p. 2) argument that early childhood degrees should incorporate "stress factors" for children as well as "risks within the environment" as one of the four defining principles of programme development. Given that younger children are more vulnerable to risk factors for abuse (Lazenbatt, 2010), failure to adequately incorporate this training need and prepare early childhood students about the risk factors of maltreatment from first year can make it difficult for them to identify abuse and know when to report a concern during pre-service professional experience situations (Clarke \& Healey, 2006; Sinclaire Taylor and Hodgkinson, 2001).

\subsection{Practice issues}

According to Walsh and Farrell (2008) it is much more difficult to respond to child protection in practice if professionals do not understand the broader context of maltreatment and impact on children. Given the low level of knowledge related to risk factors for maltreatment, it is perhaps understandable yet still of concern that early childhood students in this study also demonstrated a significantly lower knowledge score for practice issues, as a theme, when compared to their student teacher counterparts. Even after training, a minority demonstrated awareness of their role in the child protection process and subsequent attendance at child protection case conferences. While the latter may be viewed as a post-qualifying training requirement, others warn that lack of preparation for practical child protection work might, in some cases, contribute to professional barriers to reporting in the first place (Bunting, Lazenbatt \& Wallace, 2010). Baginsky (2003) also suggests that pre-service preparation of this kind will provide the foundation for continued professional development requirements and help support educators in meeting their responsibility to protect children from maltreatment and other adversities. 
In Northern Ireland, the responsibility of early childhood educators to report child protection concerns to designated staff within their own organisation is explicit in legislation (e.g. Children (Northern Ireland) Order 1995; Safeguarding Vulnerable Groups (Northern Ireland) Order 2007) as well as in educational policy (e.g. ACPC, 2005; CPSSS \& DE, 2007; DENI, 1999). If a child protection investigation is required following this initial internal report, the designated person must inform one of three agencies with the legal power to do so, namely the Gateway Team (formerly Child and Family Social Services), the Police Service Northern Ireland (PSNI) or the NSPCC (ACPC, 2005). This information was covered in depth during the course of programme delivery yet the vast majority of ECS students could not recall the accurate reporting procedures in early years settings even after training.

Failure to report a child protection concern internally will inevitably prevent the appropriate investigation from taking place. Consistent with previous studies (Clarke \& Healey, 2006; Kenny, 2004) this troubling result indicates an urgent need for further information or training required in this regard.

\subsection{Legal and policy context}

Given their access to the child population, a welcome finding from this study was that students from both groups clearly identified their unique role in child protection in education and care settings. TEd students, however, were much more aware of their legal role in child protection processes and recognised the importance of child welfare, contained within local legislation, compared to ECS students. These findings are surprising since the importance of students learning about and understanding child welfare legal and policy frameworks features prominently in the subject benchmark statements for early childhood studies degrees across the UK (QAA, 2007). This supports international thinking that early childhood educators should be provided with a discipline specific childhood maltreatment knowledge base, including the legal and policy context, as a compulsory part of their preservice training (Briggs \& Potter, 2004; McKee \& Dillenburger, 2009; Walsh \& Farrell, 2008). 
The fact that significantly less ECS students understood the paramouncy principle and key components of the child welfare checklist of the Children (Northern Ireland) Order 1995, the overarching childcare legislation for this professional group, it seems unlikely that they will understand their new statutory duty to safeguard children in practice (Safeguarding Board (Northern Ireland) Act 2011). Making a formal diagnosis of trauma related symptoms requires assessment and evaluation by a qualified health professional. However, educators have a legal role in the identification, reporting and responding process (CPSSS \& DE, 2007; Safeguarding Vulnerable Groups (NI) Order 2007). Not to address this education and training need might leave early childhood educators to work, at a national level, within their own subjective interpretations of the law. At a local level, lack of knowledge of legal and policy directives has the potential to undermine positive outcomes for young children because of an inconsistent approach and, by default, can allow child maltreatment to continue (McCallum, 2003; McKee, 2009).

\subsection{Policy and practice implications}

Each of the four UK jurisdictions includes safety needs in their overarching frameworks for children and young people. The six high level outcomes of the 'Ten Year Strategy' (OFMDFM, 2006) and the HM Government (2005) report 'Core Knowledge and Skills' provide a useful benchmark for the wider child care workforce but there is a clear need for pre-service child protection and safeguarding education policy direction specifically for intending early childhood educators. The subject benchmark statements for early childhood degrees make clear the importance of pre-service preparation in child protection, safeguarding and child welfare (QAA, 2007); yet, without a clear mandate, higher education institutions seem destined to use their own subjective interpretation of how students should be trained in and prepared for their legal role in protecting young children.

Despite the best efforts of government by way of child protection and safeguarding legislation and policy developments, younger children in particular continue to experience abuse and neglect and continue to have unmet needs (Lazenbatt, 2010; NSPCC, 2009). Teacher educators and child 
care training providers continue to rely upon setting, department and regional child protection policies and procedures only to help when developing preservice child maltreatment and protection content. Although similar in terms of children's fundamental right to protection (UN, 1989), procedures for child protection response are not the same as child protection training content. Policies and guidelines that assist and clarify the role of higher education in child protection and safeguarding education are urgently needed. These also need to be specific to child maltreatment recognition, response and support during school based work and placement experiences. A useful starting point would be to acknowledge the recent Children's Workforce Development Council [CWDC] (2010) review of the common core of knowledge and skills described earlier (HM Government, 2005). The most significant request by children, young people, families and professionals $(n=981)$ was that the common core (which includes child protection under the umbrella term safeguarding) is "built into initial training within the children's workforce" (CWDC, 2010, p. 7).

Findings presented here coupled with international research indicates that without appropriate pre-service preparation early childhood educators will remain unaware of the true extent of their child protection role in practice. More importantly, lack of early preparation i.e. from first year of undergraduate study, means that students are expected to engage in school-based work or placement experiences without any formal child maltreatment and protection knowledge. ECS students would benefit from greater inclusion of compulsory child protection training for a number of reasons. Younger children are much more vulnerable to abuse and failure to prepare early childhood educators might contribute to ineffective child abuse identification and more importantly, inappropriate response. Children who suffer child maltreatment commonly develop reactions that affect their daily lives long after the traumatic event has ended. Another implication for practice, therefore, relates to the misconception that children are all resilient and somehow cope when abused. Adequately training early childhood educators and other educational personnel can help prepare them to cope with maltreatment by understanding 
the context and impact of trauma and learning how to support children through the after-affects of abuse, neglect and exposure to family violence.

\section{Limitations and Future Directions}

\subsection{Limitations}

Like all research, this study is not without limitations. Data were based on a relatively small sample of convenience and because of training programme content may not be generalisable to other professional groups. While the programme included prevention within the content, the CPQE did not test preservice early childhood educators' knowledge of the topic nor did it explore the transfer of knowledge to practice situations. The study indicates programme effectiveness in the light of student knowledge gains; however more rigorous research designs using control groups, larger samples and/or international comparisons between programmes (in terms of content, location and delivery) might complement an evaluation of effectiveness. Another limitation might be that an indepth exploration of programme content and location was beyond the scope of this paper. This might explain why some MCQs are under-represented in this evaluation and why neither programme content nor location has received the exposure they no doubt deserve. However, by taking account of these limitations, a number of future practice and research directions are identified.

\subsection{Future directions}

The study provides evidence of the effectiveness of pre-service child protection preparation in improving students' knowledge in key child maltreatment and protection themes, as well as identifying future training needs of intending early childhood educators. Findings have influenced current practice and research on the content, location, delivery and effectiveness of the Pastoral Pathways programme and opened a longoverdue discussion on pre-service child protection training for educators in Northern Ireland for the first time. As a result, Pastoral Pathways has been extended in the Teacher Education (primary) curriculum to a 15-hour programme over a 3-year period and includes both integrated and comprehensive content to address the original six key themes in more depth, 
in addition to early intervention and prevention practice. A discrete and much shorter programme of study has been designed for and recently delivered to early childhood students on a voluntary basis. Evaluations of the two approaches to pre-service child protection preparation are ongoing and will be reported in due course, first in terms of programme location in the undergraduate curriculum and second from the viewpoint of participants.

\section{Conclusion}

Most member states of the United Nations recognise their obligation to promote children's fundamental right to protection. While a legal mandate for child protection training is commendable, research continues to identify sporadic and inconsistent child protection and safeguarding components in the undergraduate education curriculum in the UK and internationally. Early childhood educators should be able to learn about, understand and reflect on child protection practice in education but only if those charged with preparing them for entry into their professional career acknowledge the need for development in the undergraduate curriculum. There is clearly an empirical base for more research and for providing child protection training to intending early childhood educators. This argument is strengthened by the fact that all children have the right to protection; younger children are more vulnerable to maltreatment; and there is limited evidence available on programme effectiveness internationally. Higher education providers, student educators and policy makers have much to learn so that child protection is to be given the attention it deserves in the early years of school. 
References

Alvarez, K. M., Donohue, B., Carpenter, A., Romero, V., Allen, D. N. \& Cross, C. (2010). Development and Preliminary Evaluation of a Training Method to Assist Professionals in Reporting Suspected Child Maltreatment. Child Maltreatment, 15 (3), 211-218.

Anthonysamy, A. \& Zimmer-Gembeck, M. J. (2007) Peer status and behaviours of maltreated children and their classmates in the early years of school. Child Abuse and Neglect, 31 (9), 971-991.

Area Child Protection Committees. [ACPC] (2005 and Amendments 2008). Regional Policy and Procedures. Belfast: ACPC.

Arnold, L. \& Maio-Taddeo, C. (2007). Preparing teachers to meet the educational needs of children experiencing adversity: A National Perspective. Proceedings of the 2007 Australian Teacher Education Association Conference, 9-17.

Arnold, L. \& Maio-Taddeo, C. (2008). Professionals Protecting Children. Child Protection and Teacher Education in Australia. South Australia: Australian Centre for Child Protection, University of South Australia.

Baginsky, M. (2003). Newly qualified teachers and child protection: a survey of their views, training and experiences. Child Abuse Review, 12, 119-127.

Baginsky, M. \& Macpherson, P. (2005). Training Teachers to Safeguard Children: Developing a Consistent Approach. Child Abuse Review, 14, 317-330.

Bandura, A. (1977). Social Learning Theory. Englewood Cliffs, NJ: Prentice Hall.

British Educational Research Association. [BERA] (2004). Revised Ethical Guidelines for Educational Research. London: BERA.

Bevans, K., Cerbone, A. B \& Overstreet, S. (2005). Advances and Future Directions in the Study of Children's Neurobiological Responses to Trauma and Violent Exposure. Journal of Interpersonal Violence, 20 (4), 418-425.

Bishop, A., Lunn, P. \& Johnson, K. (2002) 'I would just like to run away and hide, but I won't!' Exploring attitudes and Perceptions on Child Protection Issues with Early Years Teacher Trainees on the Threshold of the Careers. Westminster Studies in Education, 25 (2), 187-199.

Briggs, F. \& Potter, G. (2004). Singaporean early childhood teachers' responses to myths about child abuse. Early Child Development and Care, 174 (4), 339-355.

Buckley, H. \& McGarry, K. (2010). Compliance with Guidelines: A Case Study of Child Protection in Schools. Irish Journal of Family Law, 13 (1), 3.

Buckley, H. \& McGarry, K. (2011). Child Protection in Primary Schools: a contradiction in terms or a potential opportunity?. Irish Educational Studies, 30 (1), 113-128.

Bunting, L. (2011) The prevalence of infant abuse and maltreatment related deaths in the UK. Leicester: NSPCC.

Bunting, L., Lazenbatt, A. \& Wallace, I. (2009). Information sharing and reporting systems in the UK and Ireland: Professional barriers to reporting child maltreatment concerns. Child Abuse Review, 19 (3), 187-202.

Child Protection Support Services in Schools [CPSSS] \& DE (2007). The School Governor's Handbook. Child Protection. Belfast: CPSSS \& DE. 
Children's Workforce Development Council [CWDC] (2010). The common core revised. London: CWDC.

Clarke, M. \& Healey, J. B. (2006) Effectiveness of pre-service child protection training: student teacher attitudes, perceptions and knowledge. International Journal of PEPE, 9 (1), 46-60.

Creedan, K. (2008). Brain functioning and dynamics involved in problematic or abusive behaviour. Worchester, MA: Massachusetts Department of Education.

Department of Education, Northern Ireland [DENI] (1999). Pastoral Care in Schools: Child Protection. Belfast: DENI.

Department for Education and Science [DfES] (2003). Every Child Matters. London: DfES.

Department for Education and Science [DfES] (2006). Working Together to Safeguard Children: A guide to inter-agency working to safeguard and promote the welfare of children. London: The Stationary Office.

Department of Health [DoH] (2002). Safeguarding Children: A Joint Chief Inspectors' Report on Arrangements to Safeguard Children. London: Joint Chief Inspectors of Social Services Inspectorate, Commission for Health Improvement, OfSTED, Probation, Prisons, Police and Magistrates Courts.

Department of Health, Social Services and Public Safety [DHSSPS] (2003). Co-operating to Safeguard Children. Belfast: DHSSPS.

Finkelhor, D. (2008). Childhood victimization. Violence, crime and abuse in the lives of young people. Oxford: Oxford University Press.

Geddes, H. (2003). Attachment and the child in school. Part 1. Emotional and Behavioural Difficulties, 8 (3), 231-242.

General Teaching Council, Northern Ireland [GTCNI] (2007). Teaching: the Reflective Profession. Belfast, GTCNI.

Gilbert, R., Kemp, A., Thoburn, J., Sidebotham, P., Radford, L., Glaser, D. \& MacMillan, H.L. (2009) Recognising and responding to child maltreatment. The Lancet, 373 (9658, 167-180.

Gilbert, R., Spatz Widom, C., Browne, K., Fergusson, D., Webb, E. \& Janson, S. (2009) Burden and consequences of child maltreatment in high-income countries. The Lancet, 373 (9657), 68-81.

Goldman, J. D. G. (2007). Primary school student-teachers' knowledge and understandings of child sexual abuse and its mandatory reporting, International Journal of Educational Research, 46, 368-381.

Goldman, J. D. G. (2010). Australian undergraduate primary school student-teachers' responses to child sexual abuse and its mandatory reporting. Pastoral Care in Education, 28 (4), 283-294.

Goldman, J. D. G. \& Grimbeek, P. (2009). How university student-teachers for primary school learn about Department of Education Policy on child sexual abuse, and mandatory reporting: the sources of their professional information. Higher Education, 58, 221-239.

Goldman, J. D. G. \& Grimbeek, P. (2011). Sources of knowledge of departmental policy on child sexual abuse and mandatory reporting identified by primary school student-teachers. Educational Review, 63 (1), 1-18. 
Higher Education Statistic Agency [HESA] (2011). Statistics - Students and qualifiers at UK HE institutions. Retrieved from the web 24/2/2011

www.hesa.ac.uk/index.php/content/view.1897/239/.

HM Government (2005). Common Core of Knowledge and Skills. London: DfES.

Hodgkinson, K. \& Baginsky, M. (2000). Child protection training in school-based initial teacher training: A survey of school-centred initial teacher training courses and their trainers.

Education Studies, 26 (3), 269-279.

Holt, S., Buckley, S. \& Whelan, S. (2008). The impact of exposure to domestic violence on children and young people: A review of the literature. Child Abuse and Neglect, 33 (7), 797810.

Kasiram, M. \& Khosa, V. (2008). Trauma counselling: Beyond the individual. International Social Work, 52 (2), 220-232.

Kenny, M. C. (2004). Teachers attitudes toward and knowledge of child maltreatment. Child Abuse and Neglect, 28 (12), 1311-1319.

Kenny, M. C. (2007). Web-based training in child maltreatment for future mandated reporters, Child Abuse and Neglect, 31 (6), 671-678.

Kirk, G. \& Broadhead, P. (2007). Every Child Matters and Teacher Education: Towards a UCET Position Paper. London: Universities Council for the Education of Teachers.

Lazenbatt, A. (2010). The impact of abuse and neglect on the health and mental health of children and young people. Belfast, NSPCC.

McCallum, F. (2003). Listening to pre-service teachers: what they need to be more effective in child protection work. Ninth Australasian Conference on Child Abuse and Neglect: Many Voices, Many Choices. Sydney, NSW.

McKee, B. E. (2003). Child protection training and early years education. Developing the EYQCP (Early Years Questionnaire on Child Protection) to identify training needs. European Educational Research Association Conference, University of Hamburg, Germany (Sept).

McKee, B. E. (2009). Childhood maltreatment: Developing a child protection training programme for student educators. Belfast: PhD Thesis, Queen's University Belfast.

McKee, B. E. \& Dillenburger, K. (2009). Child abuse and neglect: Training needs of student teachers. International Journal of Educational Research, 48 (5), 320-330.

NSPCC (2003). Learning to Protect: A child protection resource pack for teacher training. Leicester: NSPCC.

NSPCC (2004). Room for Improvement: A Manifesto for Children. London: NSPCC, the Children's Society, NCH, Barnardo's and Save the Children.

NSPCC (2009). Key child protection statistics in Northern Ireland. Belfast: NSPCC.

Office of the First Minister and Deputy First Minister [OFMDFM] (2006). Our Children and Young People - Our Pledge. A Ten Year Strategy for Children and Young People in Northern Ireland 2006-2016. Belfast: OFMDFM.

Penter, C., Cant, R. \& Clare, B. (2005). Child Protection Training Project Report for the Ministerial Advisory Council on Child Protection. Australia: Ministerial Advisory Council.

Perry, B. D. (2006). Applying Principle's of Neurodevelopment to Clinical Work with Maltreated and Traumatized Children: The Neurosequential Model of Therapies (NMT). In N. 
B. Webb (Ed), Working with Traumatized Youth in Child Welfare. New York: The Guildford Press.

Quality Assurance Agency [QAA] (2007). Subject benchmark statement: Early childhood studies. London: QAA.

Rossato, C. \& Brackenridge, C. (2009). Child Protection Training in Sport-related Degrees and Initial Teacher Training for Physical Education: An Audit. Child Abuse Review. 18 (2), 81 93.

Sinclair Taylor, A. \& Hodgkinson, F. (2001). Subjecting the Initial Teacher Training Curriculum for England and Wales to the Test of Child Protection, Teacher Development. 5 (1), 75-86.

Swenson, C. C. \& Chaffin, M. (2006). Beyond psychotherapy : Treating abused children by changing their social ecology. Aggression and Violent Behaviour. 11, 120-137.

Taylor, N. \& Siegfried, C. B. (2005). Helping Children in the Child Welfare System Heal from Trauma: A Systems Integration Approach. Durham NC: National Centre for Child Traumatic Stress.

Terr, L. (1990). Childhood Traumas: An Outline and Overview. American Journal of Psychiatry. 148 (1), 10-20.

United Nations [UN] (1989). The Convention on the Rights of the Child. New York: United Nations.

van der Kolk, B. A. (2005). Childhood Trauma: Our largest preventable public health issue. Massachusetts Legislature - Closing the Achievement Gap: Removing Trauma as a Barrier to Learning (March).

Walsh, K. and Farrell, A. (2008). Identifying and evaluating teachers' knowledge in relation to child abuse and neglect: A qualitative study with Australian early childhood teachers. Teacher and Teacher Education, 24, 585-600.

Walsh, K., Laskey, L., Mclnnes, E., Farrell, A., Mathews, B. \& Briggs, F. (2011). Locating child protection in preservice teacher education. Australian Journal of Teacher Education, 36 (7), 31-58.

Werlkerle, C., Leung, E., Wall, A., MacMillan, H., Boyle, M., Trocme, N. \& Waechter, R. (2009). The contribution of childhood emotional abuse to teen dating violence among child protective services-involved youth. Child Abuse and Neglect, 33 (1), 45-58.

Whitehead, M. (2003). Supporting Language and Literacy Development in the Early Years. Manchester: Open University Press.

World Health Organisation [WHO] (2002) Child abuse and neglect. Geneva: WHO. 
Table 1.

Participant Sample and Undergraduate Group

\begin{tabular}{|l|r|r|r|}
\hline Group & Registered students & Participating students & Total \% \\
\hline TEd Primary & 97 & 71 & $73 \%$ \\
\hline ECS & 49 & 30 & $61 \%$ \\
\hline Sample total & 146 & 101 & $69.18 \%$ \\
\hline
\end{tabular}


Table 2.

Sequence of training, semester of delivery and sample of content

\begin{tabular}{|c|c|c|}
\hline $\begin{array}{l}\text { Training } \\
\text { session }\end{array}$ & $\begin{array}{l}\text { Semester of } \\
\text { delivery }\end{array}$ & Sample of content \\
\hline 1 & Autumn & $\begin{array}{l}\text { Context and Impact of Maltreatment } \\
\text { The emotional context of abuse, neglect, violence (for } \\
\text { child, parent, educator); the unique role of educators } \\
\text { (skills, knowledge, location); child protection statistics } \\
\text { (prevalence, incidence); understanding and recognising } \\
\text { abusive behaviour (physical, sexual, emotional, neglect, } \\
\text { family violence, bullying); risk factors for abuse (socio- } \\
\text { economic status, mental health, substance abuse); legal } \\
\text { and moral duty to protect (agency, regional) }\end{array}$ \\
\hline 2 & Spring & $\begin{array}{l}\text { Considering Practice1 } \\
\text { Identifying indicators (physical, behavioural) and symptoms } \\
\text { of maltreatment; recognising abused children in settings; } \\
\text { responding appropriately directly to children (disclosure } \\
\text { response, internal reporting) and other professionals } \\
\text { (external reporting, multiagency collaboration) }\end{array}$ \\
\hline 3 & Autumn & $\begin{array}{l}\text { Conceptual and Theoretical Frameworks } \\
\text { The legal and policy context; messages from research } \\
\text { locally, nationally and internationally; protecting vulnerable } \\
\text { (e.g. disabled) children; direct work with children, young } \\
\text { people, families and other professionals (supporting } \\
\text { families, protecting children, alternative education } \\
\text { providers) }\end{array}$ \\
\hline 4 & Spring & $\begin{array}{l}\text { Considering Practice } 2 \\
\text { The concept of safety education (preventative education); } \\
\text { teaching self protection and safety skills in schools and } \\
\text { early years settings (rationale for curriculum integration, } \\
\text { teaching methodologies and pedagogies); direct work } \\
\text { with children and young people }\end{array}$ \\
\hline 5 & Autumn & $\begin{array}{l}\text { Direct work } \\
\text { Pastoral role of extended schools initiatives; multiagency } \\
\text { collaboration; assessment of need (child's needs, } \\
\text { parenting capacity to meet needs, wider family and } \\
\text { environment factors); policy developments impacting on } \\
\text { education and care practice; integrating child protection into } \\
\text { the school and early years curriculum (developing } \\
\text { preventative education through arts-based education) }\end{array}$ \\
\hline 6 & Spring & $\begin{array}{l}\text { Consolidation } \\
\text { Open discussions; debates; questions and reflections; } \\
\text { recap on previous sessions; design and discussion on case } \\
\text { scenarios (student led); update information as relevant }\end{array}$ \\
\hline
\end{tabular}

NB: Further details of programme content may be obtained from the first author 
Table 3 Group percentage scores in CPQE MCQs by themes and by student groups

\begin{tabular}{|c|c|c|c|c|c|c|c|c|c|c|c|c|c|}
\hline \multicolumn{14}{|c|}{ MCQs within Theme } \\
\hline \multicolumn{2}{|c|}{ Groups } & \multicolumn{2}{|c|}{ Prevalence } & \multicolumn{2}{|c|}{ Fatalities } & \multicolumn{2}{|c|}{ Impact } & \multicolumn{2}{|c|}{ Indicators } & \multicolumn{2}{|c|}{ Female SA } & \multicolumn{2}{|c|}{ THEME } \\
\hline Type & No. & Pre- & Post- & Pre- & Post- & Pre- & Post- & Pre- & Post- & Pre- & Post- & Pre- & Post- \\
\hline TEd & 71 & 32 & 59 & 28 & 80 & 15 & 62 & 58 & 65 & 37 & 73 & 34 & 68 \\
\hline ECS & 30 & 30 & 47 & 20 & 53 & 50 & 87 & 63 & 87 & 47 & 63 & 42 & 67 \\
\hline \multicolumn{14}{|c|}{ Theme 2. Risk Factors } \\
\hline \multicolumn{14}{|c|}{ MCQs within Theme } \\
\hline \multicolumn{2}{|c|}{ Groups } & \multicolumn{2}{|c|}{ Mental health } & \multicolumn{2}{|c|}{ Parenting } & \multicolumn{2}{|c|}{ Social skills } & \multicolumn{2}{|c|}{$\begin{array}{l}\text { Multiple } \\
\text { factors }\end{array}$} & \multicolumn{2}{|c|}{ Adversities } & \multicolumn{2}{|c|}{ THEME } \\
\hline Type & No. & Pre- & Post- & Pre- & Post- & Pre- & Post- & Pre- & Post- & Pre- & Post- & Pre- & Post- \\
\hline TEd & 71 & 42 & 69 & 13 & 50 & 23 & 51 & 35 & 79 & 59 & 69 & 34 & 64 \\
\hline ECS & 30 & 47 & 70 & 3 & 30 & 7 & 37 & 50 & 57 & 53 & 63 & 32 & 51 \\
\hline \multicolumn{14}{|c|}{ Theme 3. Indicators } \\
\hline \multicolumn{14}{|c|}{ MCQs within Theme } \\
\hline \multicolumn{2}{|c|}{ Groups } & \multicolumn{2}{|c|}{ Behavioural } & \multicolumn{2}{|c|}{ Physical } & \multicolumn{2}{|c|}{ Emotional } & \multicolumn{2}{|c|}{ Physical } & \multicolumn{2}{|c|}{ Health } & THEN & \\
\hline Type & No. & Pre- & Post- & Pre- & Post- & Pre- & Post- & Pre- & Post- & Pre- & Post- & Pre- & Post- \\
\hline TEd & 71 & 94 & 97 & 13 & 38 & 85 & 83 & 20 & 51 & 31 & 56 & 49 & 65 \\
\hline ECS & 30 & 97 & 100 & 13 & 70 & 77 & 73 & 30 & 13 & 33 & 63 & 50 & 64 \\
\hline Theme & Reco & ition & & & & & & & & & & & \\
\hline & & & & & & Qs wi & n Them & & & & & & \\
\hline Groups & & Intent & & Negl & & Learr & & Phys & & Sexua & & THEN & \\
\hline Type & No. & Pre- & Post- & Pre- & Post- & Pre- & Post- & Pre- & Post- & Pre- & Post- & Pre- & Post- \\
\hline TEd & 71 & 17 & 72 & 65 & 72 & 75 & 94 & 89 & 99 & 61 & 77 & 61 & 83 \\
\hline ECS & 30 & 30 & 73 & 47 & 70 & 90 & 97 & 53 & 57 & 67 & 80 & 57 & 75 \\
\hline Theme & Pract & & & & & & & & & & & & \\
\hline & & & & & & Qs wi & n Them & & & & & & \\
\hline Groups & & Repor & & Infor| & & Multi & ency & Inves & gation & Obser & ations & THEN & \\
\hline Type & No. & Pre- & Post- & Pre- & Post- & Pre- & Post- & Pre- & Post- & Pre- & Post- & Pre- & Post- \\
\hline TEd & 71 & 49 & 99 & 38 & 77 & 45 & 94 & 20 & 79 & 73 & 86 & 45 & 87 \\
\hline ECS & 30 & 40 & 67 & 47 & 83 & 43 & 23 & 13 & 20 & 70 & 83 & 43 & 55 \\
\hline Theme & Legal & Ollcy c & & & & & & & & & & & \\
\hline & & & & & & Qs wi & n Them & & & & & & \\
\hline Groups & & Paran & ountcy & Educ & ional & Socia & care & Child & elfare & Indivic & & THEN & \\
\hline Type & No. & Pre- & Post- & Pre- & Post- & Pre- & Post- & Pre- & Post- & Pre- & Post- & Pre- & Post- \\
\hline TEd & 71 & 42 & 73 & 54 & 99 & 41 & 63 & 28 & 76 & 86 & 99 & 50 & 80 \\
\hline ECS & 30 & 33 & 57 & 50 & 57 & 60 & 33 & 47 & 50 & 87 & 100 & 55 & 59 \\
\hline
\end{tabular}


Table 4.

Descriptive statistics in relation to three CPQE post-test theme scores for two groups

\begin{tabular}{|c|c|c|c|c|}
\hline $\begin{array}{l}\text { Dependent variable } \\
\text { (theme) }\end{array}$ & Groups & $\begin{array}{l}\text { Pre-test } \\
\text { mean }\end{array}$ & $\begin{array}{l}\text { Post- } \\
\text { test } \\
\text { mean }\end{array}$ & $\begin{array}{l}p \text {-value } \\
\text { (Mann- } \\
\text { Whitney U- } \\
\text { test) }\end{array}$ \\
\hline \multirow[t]{2}{*}{ Risk factors } & TEd & 51.83 & 55.94 & \\
\hline & ECS & 49.03 & 39.32 & $<0.05$ \\
\hline \multirow[t]{2}{*}{ Practice issues } & TEd & 52.45 & 63.27 & \\
\hline & ECS & 47.57 & 24.32 & $<0.001$ \\
\hline \multirow[t]{2}{*}{ Legal/policy context } & TEd & 48.85 & 59.07 & \\
\hline & ECS & 56.10 & 31.90 & $<0.001$ \\
\hline
\end{tabular}

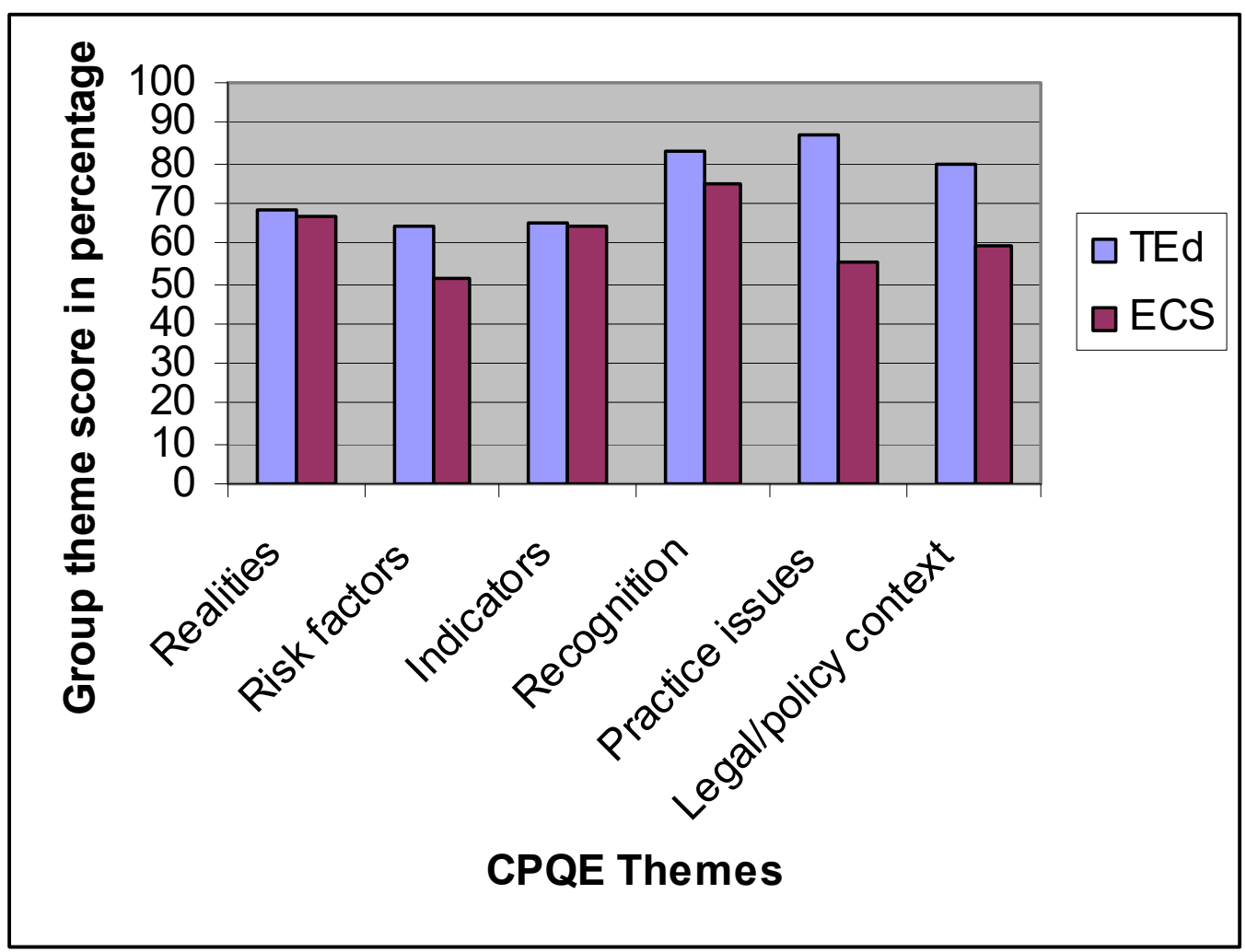

Figure 1. A comparison of post-test correct theme scores for two groups in percentage 